\title{
On Vertical Drag Defects Formation During Direct Chill (DC) Casting of Aluminum Billets
}

\begin{abstract}
TORBJÖRN CARLBERG and ANDERS E.W. JARFORS
During air-slip direct chill casting of aluminum billets, one of the major defects occurring includes traces along the billet called vertical drags (VDs). If the VDs are too deep or too many, then they cause scraping of the billets. As in the subsequent extrusion process, the surface quality is known to impair both the productivity and quality of the profiles. In cast-house practice, many theories circulate about the causes of VD defects and how to avoid them, but in the literature, no thorough treatments have been made to explain this phenomenon. In the current study, the outer appearance, structure around, and compositions at the defects are analyzed. A theory for the formation of the defects, their cause, and how their appearance is coupled to different alloy types is presented. The segregation in the vicinity of the defects is discussed based on deformation of semisolid materials and coupled to Reynolds dilatancy in granular materials. The theory can explain differences between 6063 and 6005 alloys.
\end{abstract}

DOI: $10.1007 / \mathrm{s} 11663-013-0009-4$

(C) The Minerals, Metals \& Materials Society and ASM International 2013

\section{INTRODUCTION}

A problem in the production of aluminum billets is the surface defects, which are of large importance for the subsequent extrusion of the billets to profiles. The productivity of the extrusion process is influenced by the billet surface properties, and it sets demands on the size of the segregation zone, which is the governing factor for the appearance of different phases in the surface region. Billet surface quality, for example, is evaluated by measuring surface appearance, segregate zone thickness, large $\mathrm{Mg}_{2} \mathrm{Si}$ and $\beta$-particles, and area fraction of pores near the surface. A strong improvement of billet surface quality has followed from the introduction of the air-bearing mold technology. However, the surface quality can still be a problem and certain types of defects can occur. One of the most common defects found at DC casting by the air-slip technology is vertical drag (VD) defects. This article is focused on the VD defects and is partly based on an earlier paper ${ }^{[1]}$ in which a comparison between segregation to smooth surfaces and to VD defects was made. The VD defects were shown to increase the segregation zone and change the type and amount of particles precipitated at the surface, but it was shown also that different alloys were influenced differently by the defects. It is only in a limited number of papers ${ }^{[1-4]}$ that the cause and nature of the vertical drag defect has been discussed, and a clear understanding of the defect has not evolved. It has been recognized that the VD defects are connected to an increased surface segregation, and the occurrence of such a defect

TORBJÖRN CARLBERG, Professor, is with the Mid Sweden University, 85170 Sundsvall, Sweden. Contact e-mail: torbjorn.carlberg@ miun.se ANDERS E.W. JARFORS, Professor, is with the School of Engineering, Jönköping University, 55111 Jönköping, Sweden.

Manuscript submitted September 3, 2013.

Article published online December 17, 2013. will therefore embody the most sensitive point on the billet for formation of extrusion defects and be the limiting factor for the productivity in the subsequent processing. It is thus of importance to understand the mechanisms behind the formation of the VD defects and the thereto-coupled segregation. The current article is a study to understand such segregation based on recently published data on dilatancy in semisolid slurries. ${ }^{[5-7]}$

\section{BACKGROUND KNOWLEDGE CONCERNING VD FORMATION}

A possible cause for formation of VDs at air-slip hot top casting is that, due to uneven and/or low air pressure in the graphite ring, metal sticks to the graphite ring in the DC casting mold. It is well known from casting practice $^{[4]}$ that old graphite rings and rings, where some sections have low gas permeability, cause surface defects on the billets. In Reference 2, the meniscus and the gap between the graphite ring and meniscus was observed in situ, and it was actually seen that bridges were formed over the gap. Those bridges were associated with an immobilization of the meniscus surface and with the formation of VD defects. However, from experience from cast houses and as stated in Reference 8, the condition of the refractory transition plate also is important for the surface quality. An uneven transition plate with pits or cracks impairs the surface quality, and the amount of defects increases and problems to achieve air-slip conditions rises. Therefore, both the graphite ring and transition plate quality have to be considered in an explanation of the VD defect formation.

The effect of the transition plate is probably connected to the necessity to release oxides from the meniscus surface. At the start of the casting, when the starting-head and whole mold volume is filled, oxides 
are formed on the melt surface. These oxides have to be released from the meniscus at the beginning of the casting by strong gas flow through the graphite ring. If the transition plate has flaws, then oxides can attach to the plate and the release is hindered. The question is, how does this influence the billet surface and couple to the VD formation?

\section{EXPERIMENTAL TEST}

To obtain more information about the influence of the transition plate quality, experiments were done where 2-mm diameter $\mathrm{Al}_{2} \mathrm{O}_{3}$ rods were drilled into the transition plate in a way that they were protruding $4 \mathrm{~mm}$ out from the plate surface. Two tests were done, and the positions of the alumina rods were 30 and $15 \mathrm{~mm}$ from the graphite ring connection, i.e., from the edge of the transition plate. The tests were done during casting of 178-mm-diameter billets, where the total distance from the graphite ring to the thimble bore was $46 \mathrm{~mm}$. No signs of interaction between the protruding alumina rods and the billet surfaces could be seen during the first parts of the castings. At the end of the castings, some faint lines appeared at the actual positions. In the case where the alumina rod was $30 \mathrm{~mm}$ from the graphite ring, a line of dots could be seen close to the top of the billet (Figure 1); i.e., no typical vertical drag appeared, but rather an array of dots that was somewhat irregularly positioned.

When the alumina rod was placed closer to the edge, $15 \mathrm{~mm}$, still no VD defect appeared. Instead, a 15-mm-

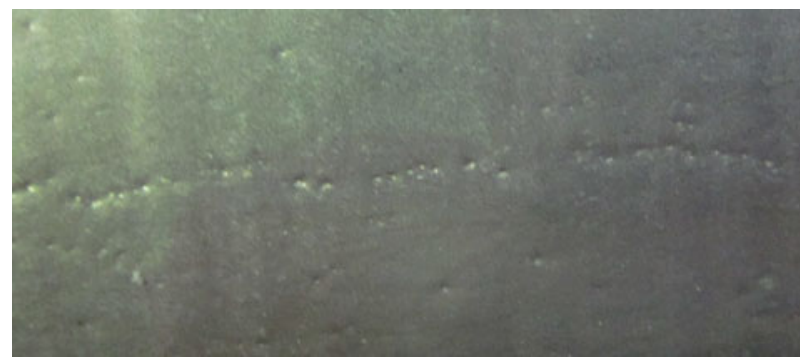

Fig. 1-Surface of billet close to the top at a position where a disturbance has been placed on the transition plate $30 \mathrm{~mm}$ from the edge. wide "band," hardly seen, revealed that the flow in the region had been disturbed. In Figure 2, the position of the alumina rod can be seen to the left and the corresponding surface defect to the right. Along the sides of the influenced zone, small oxide patches 2 to 3 $\mathrm{mm}$ in size can be seen, but this was only observed at the top $2 \mathrm{~m}$ of the billet.

\section{SEGREGATION AND STRUCTURE}

In Reference 1, quantitative measurements of the surface segregation to VD defects were compared to segregation at smooth, defect-free surfaces. It was shown that a significantly increased segregation occurred at VD defects compared to defect-free surfaces in a 6063 alloy (Figure 3), while in a 6005 alloy, no difference in surface segregation between smooth surface and a VD was detected (Figure 4). Alloy compositions are shown in Table I. In Reference 1, the structure associated with the VD defects mostly were studied in transverse cuts, which also clearly show the same segregation differences as the quantitative profiles, i.e., enhanced segregation to VDs only for the 6063 alloy.

It is very important to recognize that when studying the structure around a defect in a transverse cut, it is not always representative for the whole defect; when a defect is studied in longitudinal cut, strong periodic variations in segregation are revealed. In the current article, further studies of the structures, both in longitudinal and transverse cuts, in the different alloys have been done and a 6060 alloy has been included (Table I). Figure 5 compares the structures at a defect and at a smooth surface in a 6060 alloy. The segregation zone width and depth varies periodically, and sometimes stronger segregations like in the right side of Figure 5(a) occurs. At smooth surfaces, the segregation zone depth is 100 to $200 \mu \mathrm{m}$, which supports the earlier findings ${ }^{[1]}$ that the segregation is clearly stronger at the defects. In Figure 6, the structure along a VD defect in a 6005 alloy is shown, and it can be seen that the segregation along the defect is strongly varying, but at certain points along the defect protruding spots of very strong segregation, also including pores, occurs, but between those spots, very minor surface segregation can be seen. When the concentration profile along such a defect is measured, the result, which
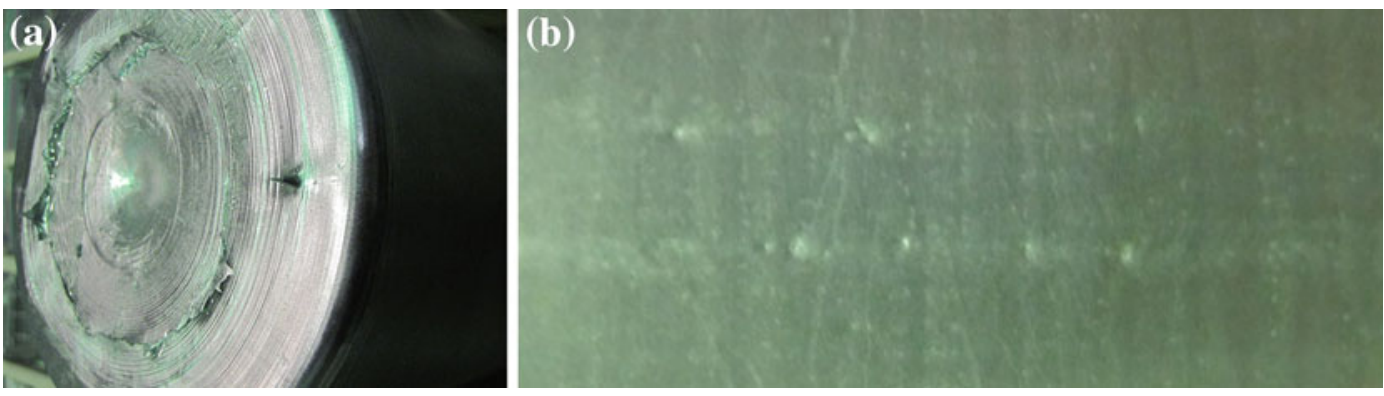

Fig. 2-The top of a billet showing the position where an alumina rod has been placed on the transition plate $15 \mathrm{~mm}$ from the edge (a) and the surface of the billet at the corresponding position $(b)$. 

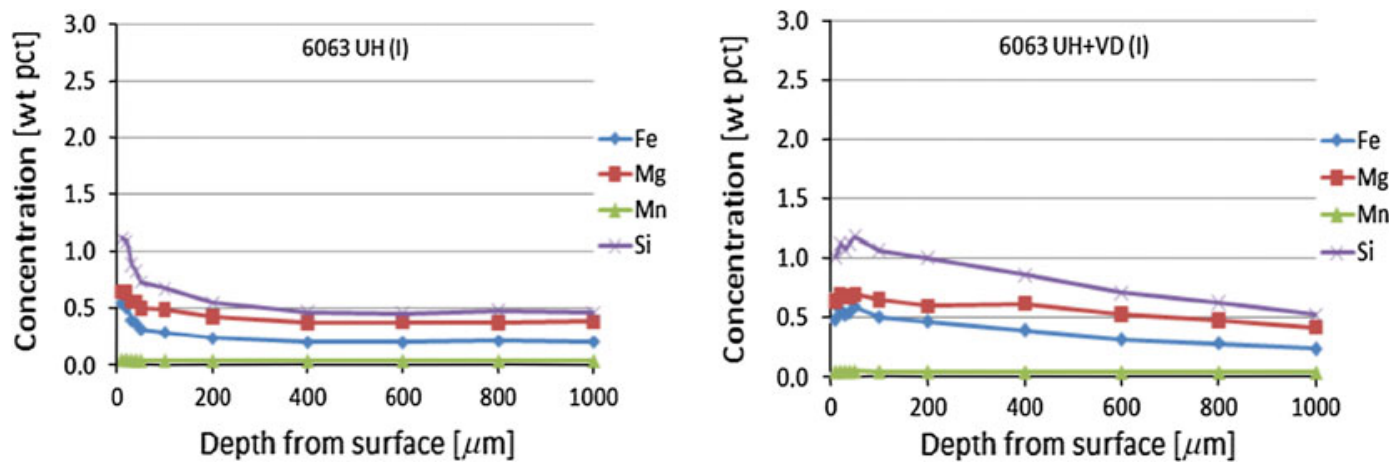

Fig. 3- Surface segregation in 6063 alloy, left diagram at smooth surface and right diagram at VD defect.
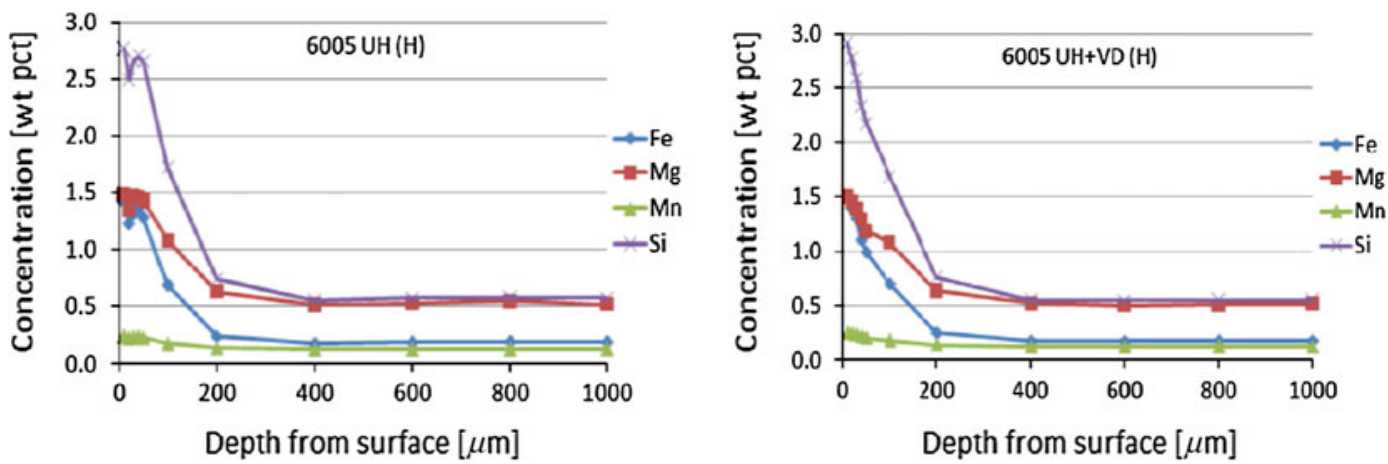

Fig. 4 - Surface segregation in 6005 alloy, left diagram at smooth surface and right diagram at VD defect.

Table I. Alloy Compositions

\begin{tabular}{ccccc}
\hline & Fe (Wt Pct) & Mg (Wt Pct) & Si (Wt Pct) & Mn (Wt Pct) \\
\hline 6060 & 0.190 & 0.391 & 0.466 & 0.025 \\
6063 & 0.186 & 0.467 & 0.436 & 0.038 \\
6005 & 0.190 & 0.525 & 0.735 & 0.072 \\
\hline
\end{tabular}

is an average value along and around the defect, will show smaller differences compared to smooth surfaces than for the 6063 alloy, as are shown in Figure 4. An interesting observation was done close to the VD defect in Figure 6(b) and it is shown in Figure 6(c), where a deeper segregation zone was found about $800 \mu \mathrm{m}$ from the defect and where the surface is smooth.

The periodicity in the structure appearance (Figures 5(a) and 6(a)) can also be seen at smooth surfaces, but there it is not as strong as at the defects. The length of the period is 2 to $4 \mathrm{~mm}$, which corresponds to about 1 to 2 seconds at normal casting speed and can be coupled to the frequency of the "rocking" of the liquid in the casting table (i.e., an effect of bubbling when the gas, pressed through the graphite ring, is escaped through the liquid in the mold top). On nondefected surfaces, this effect is seen as a weak banding, called "lapping," on the ingot surface, but at the defects, this effect is exaggerated and is coupled to strong local segregation.

\section{DISCUSSION}

\section{A. Transition Plate}

The test, with disturbances placed on the transition plate, showed that although obstacles for free flow along the plate existed, no VD defects were formed on the billets. Instead, small oxide particles or patches were released in the disturbed area (Figures 1 and 2). These surface defects are regularly observed but are regarded as being a less serious problem than the VD defects. Exactly the type of surface appearance as in Figure 2 is also often observed at positions where particles have been stacked in the gas pocket. It can therefore be concluded that these small oxide patches formed along the transition plate or in the gas pocket, i.e., where the melt under the oxide skin is totally liquid, is caused by disturbances along the transition plate, and follows the oxide skin through the mold without forming a VD defect.

\section{B. Vertical Drag Formation}

It was observed in Reference 2 that the meniscus becomes immobile and metal bridges appear in the gap between graphite ring and meniscus at positions where VD defects occur. For a VD defect to form, the contact points have to occur at a position low enough on the casting surface to interact with the solidification, i.e., in the semisolid region. Damages in the graphite rings 

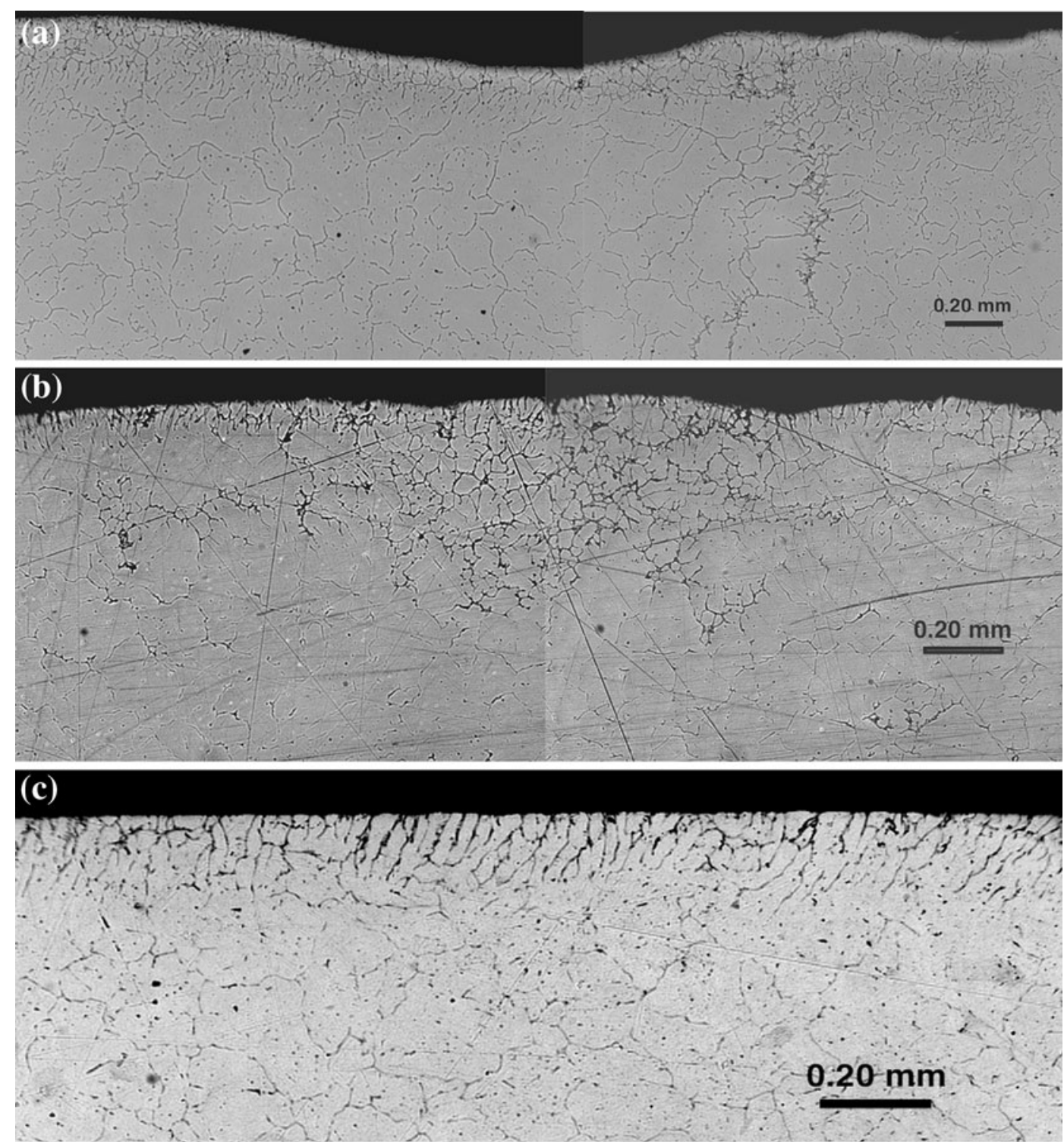

Fig. 5-The structure at the surface of a 6060 alloy. (a) A cut along a VD defect with a segregation zone depth of 200 to $300 \mu \mathrm{m}$ in the left part but a strong deep segregation to the right. (b) A transverse cut through the defect at a point where strong segregation occurs. (c) The structure along a smooth surface with no defects (observe different scale).

obstructing the gas flow on certain spots are a likely cause for VD formation, as the gas pressure will influence the meniscus stability. ${ }^{[9]}$ If the gas pressure is low and some oxide particles move along with the oxide skin, then rupture of the skin can occur and the observed $^{[2]}$ liquid bridges can appear. When a contact point has formed, the oxide skin no longer can slide unhindered along the graphite surface and the typical wrinkling of oxide along the VD defects occurs. ${ }^{[1]}$ The size and shape of the defects can vary strongly, ${ }^{[1]}$ and this is dependent on both the position and size of these bridges, but also the alloy content is important, which will be discussed in Section V-C.

\section{Segregation and Structure}

In 6060 and 6063 alloys, it is clear that VD defects strongly enhance the surface segregation compared to the segregation to a defect free surface. In classic theory of inverse segregation to a chilled surface, the segregation is driven by the shrinkage of the solidifying shell. ${ }^{[10-12]}$ In these theories, which are verified by experimental findings, see e.g., Reference 11 for an aluminum-copper alloy, the increased solute concentration is typically between 10 and 20 pct above the bulk average concentration. At the surfaces of DC cast ingots, the surface segregation is from 100 to 400 pct of the average concentrations. ${ }^{[1]}$ This is valid for both smooth surfaces and at VD defects, but while the thickness of the segregation zones varies from 50 to $100 \mu \mathrm{m}$ at a smooth surface, it can vary from 100 to $500 \mu \mathrm{m}$ at VD defects. In this article, the focus is on the VD defects, and parameters influencing the segregation to normal surfaces will be discussed in a later article. Basically, the strong segregation to the surfaces is a result of exudation and inverse solidification as was discussed in Reference 13; i.e., in the 

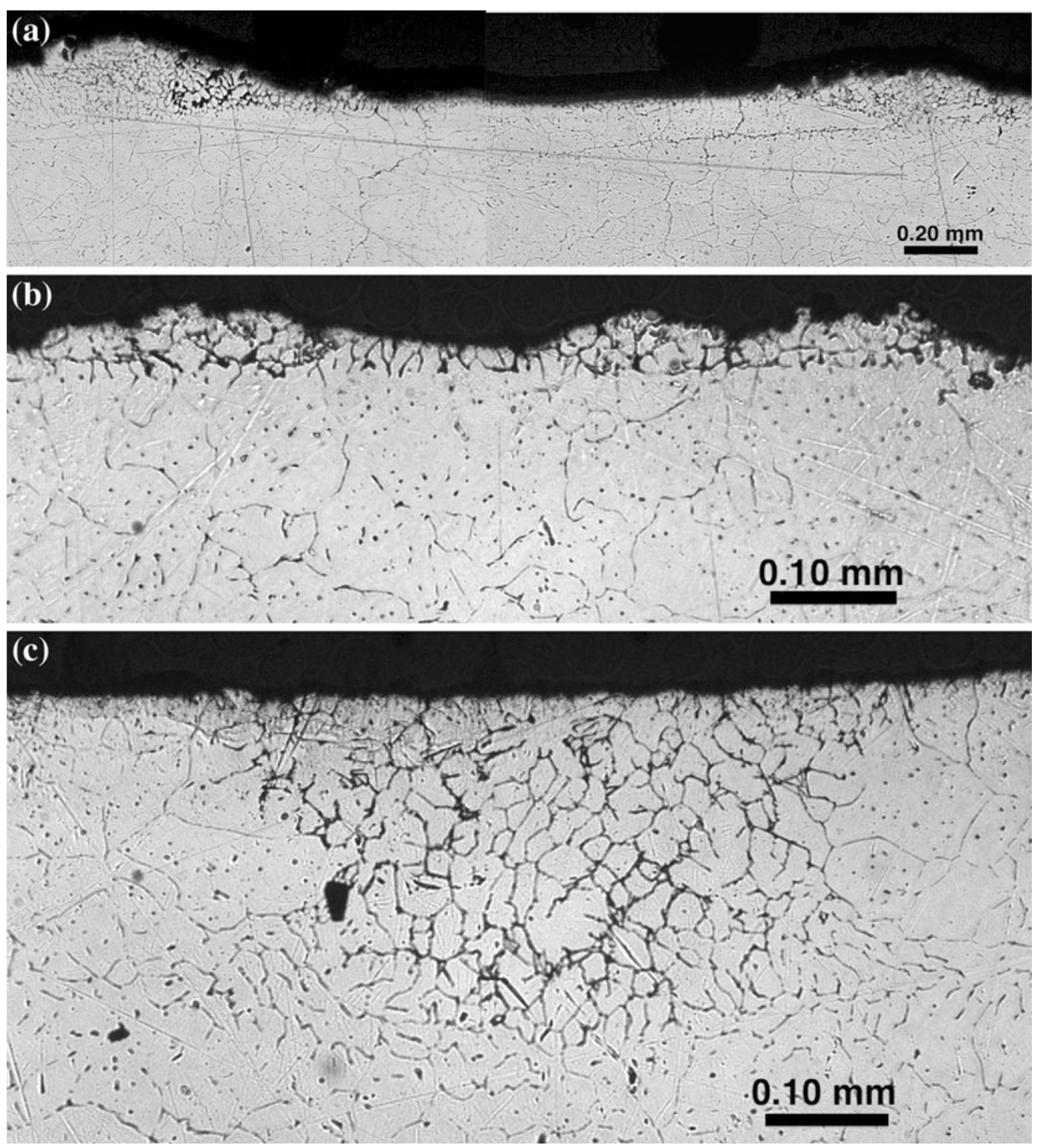

Fig. 6-The structure at the surface of a 6005 alloy. (a) A cut along a VD defect where the segregation is concentrated to protrusions along defect. (b) A transverse cut through the defect. (c) A transverse cut close to (b) but where the surface is smooth. The distance from the edge of the defect shown in (b) and edge of the shown segregation zone is about $800 \mu \mathrm{m}$.

outer shell, a thin liquid layer solidifies outward giving increased surface solute content simply due to normal segregation. In 6060 and 6063 alloys, a mechanism other than solidification shrinkage and outward solidification is probably active in driving an enhanced surface segregation to the defects.

Studying the structure around a defect in a transverse cut, as in Figure 5(b), one can see a segregation zone as well as arms or bands going out from that central segregation zone. Also looking along the defect (Figure 5(a)), i.e., along the segregation zone, an arm of high solute content is extending rather deep, about 1 $\mathrm{mm}$, into the billet. These arms indicate that the structure is under tension and that grains are separating as under initiation of cracks. The tensions are obviously not large enough for cracks to form, but enriched solute is sucked in between the separating grains and the enriched regions are formed. Such phenomena have been observed in situ in Reference 14 during deformation of $\mathrm{Al}-\mathrm{Cu}$ alloys. These arms can be seen in all alloys, also in 6005 , but there the segregation zone generally is smaller and the arms are not so frequently occurring.

In later years, it has been discussed that segregation bands can occur during deformation of metals in twophase condition in an analogy with deformation in granular materials, ${ }^{[5-7]}$ i.e., by the so-called Reynolds dilatancy. The formation of the VD defects occurs when the alloys are in a two-phase condition, and it should be possible to discuss the segregation to the VD defects in a similar way. Assuming that the defects are a result of a contact point somewhere along the graphite ring, the solidified shell will be subjected to periodic tensile stresses coupled to variations of the liquid metal 


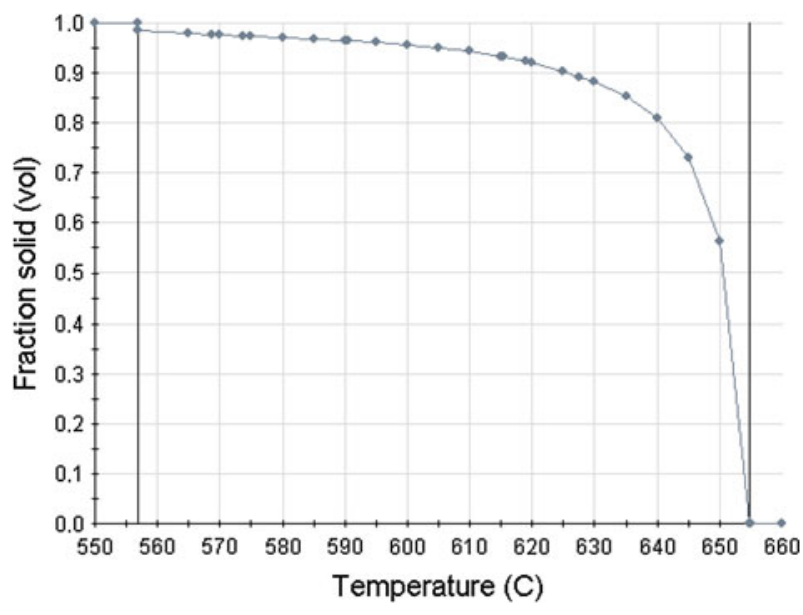

Fig. 7- Solid fractions calculated with JMatPro for a 6063 alloy.

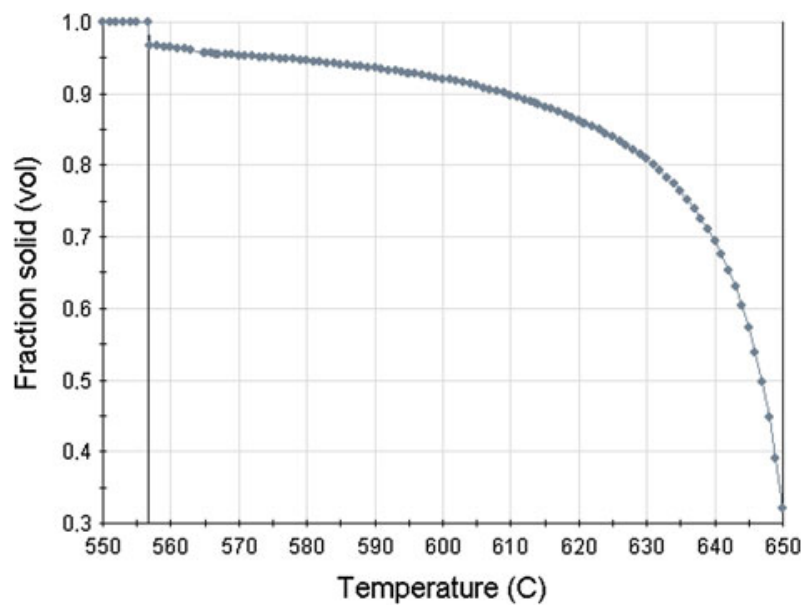

Fig. 8 - Solid fractions calculated with JMatPro for a 6005 alloy.

pressure due to the "rocking" of the liquid in the casting table. The periodic segregation pattern along the defects can thus be explained by a periodic deformation of the two-phase structure in a strained zone around the defect. The size of the segregation zones can be in the order of 10 grain sizes (Figure 5(b)), which is typical for Reynolds dilatancy around a local deformation by shearing, but if it is such a zone or just a strained zone in which enriched liquid is sucked in, then is not possible to extinguish. However, the coupling of the deformation to temperature and position in the solidification interval can be discussed in a similar way independent of what deformation mechanism it is.

In the papers discussing Reynolds dilatancy, it has been pointed out the importance of where in the solidification interval, i.e., at what fraction solid in relation to the coherency point, the material is sensitive to the deformation. It was concluded in Reference 7 that the onset of volumetric strain occurred at solid fractions above the coherency point and that the volume change in the bands increased with increasing solid fractions. In a thermodynamic analysis where solid fractions as a function of temperature are made by JMatPro (Sente Software Ltd., Surrey, U.K.) (Figures 7 and 8), it is

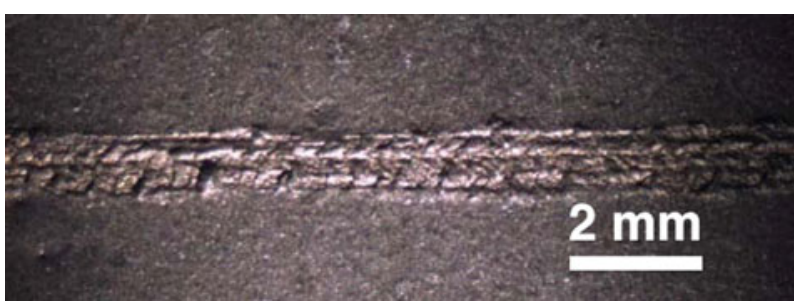

Fig. 9- Surface appearance for a VD defect in a 6005 alloy, from Ref. [1].

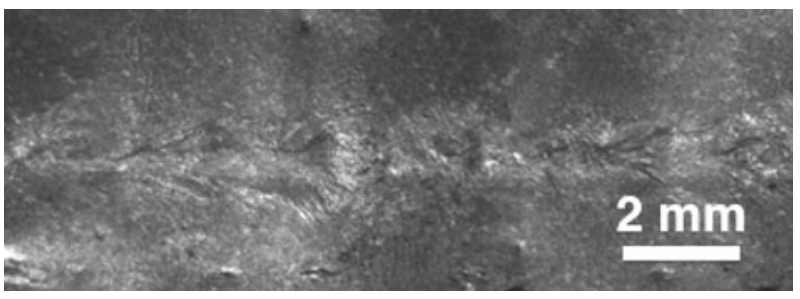

Fig. 10 - Surface appearance for a VD defect in a 6063 alloy, from Ref. [1].

clear that the fraction solid increases much faster for the 6063 alloy than for the 6005 alloy as temperature decreases and the solidification proceeds. This means that the point of coherency and thus the critical stage for the deformation is reached earlier for 6063 and at a position higher up along the graphite ring. It is also at the upper part of the ring where it is most likely that oxides will cause sticking and thus VD defects form. Also, if the casting temperature is decreased for 6005 to compensate for lower liquidus temperature, then the temperature needs to decrease clearly more for the 6005 than for the 6063 alloy before the coherency point is reached.

The coherency point for this type of alloys can be expected to be about 0.4 to $0.5^{[15]}$ as the grain refinements give grain sizes just above $100 \mu \mathrm{m}$, and at, e.g., $923 \mathrm{~K}\left(650^{\circ} \mathrm{C}\right)$, the solid fraction is 0.55 for the 6063 alloy but only 0.30 for the 6005 alloy (Figures 7 and 8). This suggests that a more coherent two-phase structure exists in the critical zone for 6063 than for 6005 , and thus at deformation the volumetric expansion is likely to be larger when the crystals are pushed away from each other, and thus the segregation will be larger.

\section{Appearance of VD Defects}

In 6005 , the segregation zone generally is small, but instead locally very strong segregation occurs to protrusions at the surface, where pores also tend to appear (Figure 6(a)). This is probably due to exudation of liquid through the dendritic network ${ }^{[16]}$ or it can even be that the deformation occurs at or below the point of coherency, and thus it easily allows the liquid to be pressed to the outside of the solidifying shell. The pores look like shrinkage pores (Figure 6(a)) and can be understood as the protrusions being solidified locally and late due to a high solute content compared to the 
surrounding structure. These phenomena probably explain why VD defects viewed on surface of billets look more severe on 6005 (Figure 9) than on 6063 billets (Figure 10). In Reference 1, many different appearances of VD defects were studied, but generally on 6005 billets, the traces were larger, which can be understood if the deformation from contact with the graphite ring is done at a lower fraction of solid. However, the segregation to the zone around the VDs for 6060 and 6063 alloys is larger although the outer appearance of the defects are smaller (Figure 10).

\section{CONCLUSIONS}

Flaws on the transition plate normally cause small oxide patches to form on the billet surface, but not VD defects. The latter are more likely formed basically due to damages in the graphite rings sometimes in combination with the oxide patches coming from disturbances along the transition plate.

The structure and segregation around VD defects are different for different alloys, and it was concluded that the relatively small differences in composition between 6063 and 6005 alloys give sufficiently large differences in solidification interval and coherency, which strongly influence the segregation and sensitivity to VD defect formation.

It was shown that although VD defects normally are larger for 6005 alloys based on the appearance on the outer surface of the billets, the segregation zones around them are normally less severe than for 6063 alloys. The latter was explained by shear band formation at a critical solid fraction where the semi-solid material is sensitive to Reynolds dilatancy.

\section{ACKNOWLEDGMENTS}

Robert Örjestål and the cast-house employees at Kubikenborg Aluminium AB are acknowledged for providing materials, facilitating experimental tests, and hosting fruitful discussions. The work was financially supported by the European Regional Development Fund.

\section{REFERENCES}

1. M. Erdegren and T. Carlberg: Light Metals, TMS, Warrendale, PA, 2011, pp. 675-80.

2. J.M. Ekenes and W.S. Peterson: Light Metals, TMS, Warrendale, PA, 1991, pp. 933-39.

3. C. Emes and R.J. Collins: Mater. Sci. Forum, 2010, vol. 630, pp. 187-91.

4. R.J. Collins: Report, RJ Collins Inc., Washington, DC, 2006.

5. C.M. Gourlay, B. Meylan, and A.K. Dahle: Acta Mater., 2008, vol. 56, pp. 3403-13.

6. C.M. Gourlay and A.K. Dahle: Nature, 2007, vol. 445, pp. 70-73.

7. B. Meylan, S. Terzi, C.M. Gourlay, and A.K. Dahle: Acta Mater., 2011, vol. 59, pp. 3091-3101.

8. Ö. Kozmas: MSc. Thesis, Royal Institute of Technology, Stockholm, Sweden, 2007.

9. F. Iversen: Ph.D. Thesis, Norwegian University of Science and Technology, Trondheim, Norway, 2002.

10. M.C. Flemings: ISIJ Int., 2000, vol. 40, pp. 833-41.

11. I.L. Ferreira, C.A. Santos, V.R. Voller, and A. Garcia: Metall. Mater. Trans. B, 2004, vol. 35B, pp. 285-97.

12. I.L. Ferreira, C.A. Siquiera, C.A. Santos, and A. Garcia: Scripta Mater., 2003, vol. 49, pp. 39-44.

13. S. Benum, A. Håkonsen, J.E. Hafsås, and J. Sivertsen: Light Metals, TMS, Warrendale, PA, 1999, pp. 737-42.

14. S. Terzi, L. Salvo, M. Suéry, N. Limodin, J. Adrien, E. Maire, Y. Pannier, M.B.D. Bernard, M. Felberbaum, M. Rappaz, and E. Boller: Scripta Mater., 2009, vol. 61, pp. 449-52.

15. N.J.M. Veldman, A.K. Dahle, D.H.S. John, and L. Arnberg: Metall. Mater. Trans. A, 2001, vol. 32A, pp. 147-55.

16. D. Mortensen, B.R. Henriksen, M. Hamdi, and H.G. Fjaer: Light Metals, TMS, Warrendale, PA, 2008, pp. 773-79. 